\title{
Endoscopic esophagogastric anastomosis using a lumen-apposing metal stent to manage an anastomotic leakage after esophagectomy
}

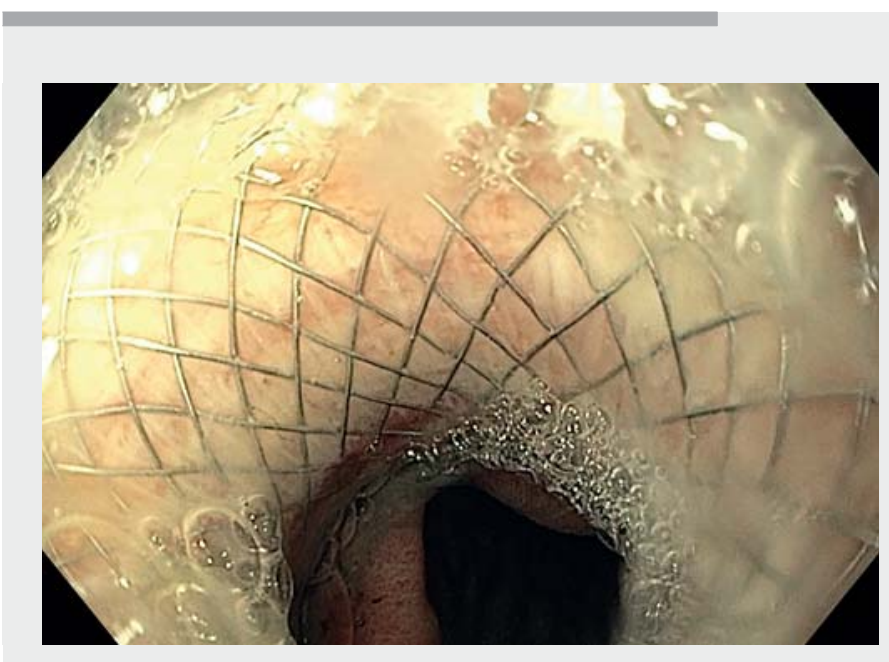

$\checkmark$ Video 1 Endoscopic esophagogastric anastomosis using a lumen-apposing metal stent to manage an anastomotic leakage after esophagectomy.

Ivor-Lewis esophagectomy (ILE) for esophageal cancer is associated with a significant risk of anastomotic leakage [1]. Recently, a lumen-apposing metal stent (LAMS) has been used to create an anastomosis between the lumen of two digestive structures [2]. An animal study showed technical feasibility of endoscopic esophagogastric anastomosis with LAMS following ILE [3]. To our knowledge, no case of anastomotic leakage managed endoscopically with LAMS has been described to date.

We describe the case of a 69-year-old man who underwent ILE for esophageal cancer. Chest computed tomography performed 2 days after surgery showed massive dilation of the stomach with high suspicion of postoperative gastroparesis and an emphysematous infiltration around the anastomosis. Gastroscopy showed a circumferential leakage of the anastomosis and the stomach lumen was impossible to find. We decided to create an endoscopic esophagogastric anastomosis with LAMS to manage this leakage and to reach the stomach in order to perform a pyloromyotomy ( $\triangleright$ Video 1 ).
Under endoscopic ultrasound, the stomach lumen was found and punctured allowing a guidewire to be placed inside. The LAMS catheter was advanced over the guidewire and the LAMS deployed with the distal flange in the stomach and the proximal flange in the esophagus (> Fig. 1, > Fig.2). Aspiration of the gastric lumen was then performed through the LAMS. Repeat upper endoscopy was performed 1 month later. After dilation of the LAMS ( $>$ Fig. 3 ), an endoscope was successfully passed through the LAMS and pyloromyotomy was performed to manage the postoperative gastroparesis.

This case illustrates the feasibility of esophagogastric anastomosis using LAMS to manage complete anastomotic leakage. In our case, this technique allowed the stomach to be reached and pyloromyotomy to be performed to manage postoperative gastroparesis. However, more data are needed to confirm the role of LAMS in the management of leakage following ILE.

Endoscopy_UCTN_Code_TTT_1AO_2AI

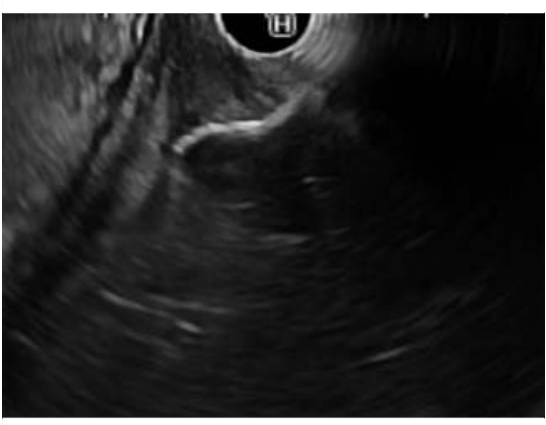

- Fig. 1 The lumen-apposing metal stent was deployed with the distal flange in the stomach and the proximal flange in the esophagus.

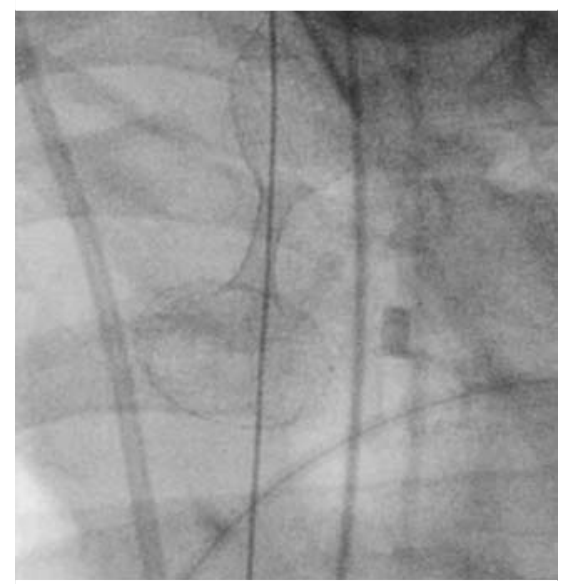

> Fig. 2 The lumen-apposing metal stent after deployment.

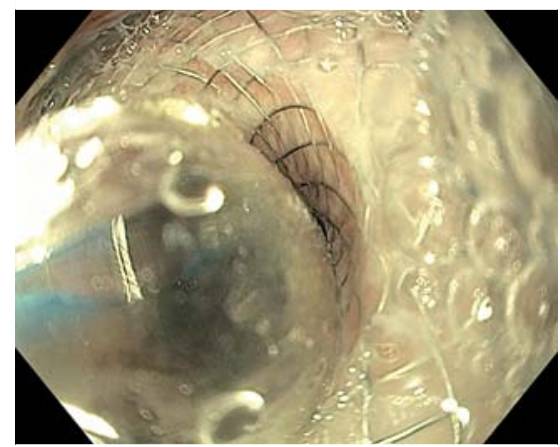

Fig. 3 Dilation of the lumen-apposing metal stent to reach the stomach. 


\section{Competing interests}

The authors declare that they have no conflict of interest.

The authors

Thomas Lambin ${ }^{1,2}$, Marion Schaefer ${ }^{3}$, Pierre Lafeuille', Florian Rostain ${ }^{1}$, Jérôme Rivory', Mathieu Pioche ${ }^{1,2}$, Thierry Ponchon ${ }^{1,2}$

1 Gastroenterology and Endoscopy Unit, Pavillon L, Edouard Herriot Hospital, Lyon, France

2 Inserm U1032, Labtau, Lyon, France

3 Gastroenterology Unit, University Hospital of Nancy, Vandoeuvre-lès-Nancy, France

\section{Corresponding author}

\section{Thomas Lambin, MD}

Endoscopy Unit - Digestive Disease

Department, Pavillon L - Edouard Herriot

Hospital, 5 place d'Arsonval, 69437 Lyon

Cedex, France

thomaslambin@hotmail.fr
[1] Van Daele E, Van de Putte D, Ceelen W et al. Risk factors and consequences of anastomotic leakage after Ivor Lewis oesophagectomy ${ }^{\dagger}$. Interact Cardiovasc Thorac Surg 2016; 22: 32-37

[2] Betés M, Pérez-Longo P, Peralta S et al. Feasibility and patency of echoendoscopic anastomoses with lumen apposing metal stents depending on the gastrointestinal segment involved. Sci Rep 2021; 11: 3992

[3] Culetto A, Gonzalez J-M, Vanbiervliet G et al. Endoscopic esophagogastric anastomosis with luminal apposition Axios stent (LAS) approach: a new concept for hybrid "Lewis Santy”. Endosc Int Open 2017; 5: E455E462
Bibliography

Endoscopy 2022; 54: E320-E321

DOI 10.1055/a-1529-5035

ISSN 0013-726X

published online 9.7.2021

(C) 2021. Thieme. All rights reserved.

Georg Thieme Verlag KG, Rüdigerstraße 14,

70469 Stuttgart, Germany

\section{ENDOSCOPY E-VIDEOS}

https://eref.thieme.de/e-videos

回店 Endoscopy E-Videos is an open access online section, 回: reporting on interesting cases and new techniques in gastroenterological endoscopy. All papers include a high quality video and all contributions are freely accessible online. Processing charges apply (currently EUR 375), discounts and wavers acc. to HINARI are available.

This section has its own submission website at

https://mc.manuscriptcentral.com/e-videos 